\title{
Design of electronic lock based on single-chip microcomputer
}

\author{
Biqing $\mathrm{Li}^{1, a}$, Zongning $\mathrm{Li}^{2, a, *}$, Chongjun Yang ${ }^{1, a}$, Shiyong Zheng ${ }^{3, \mathrm{~b}}$ \\ ${ }^{1}$ College of Mechanical and Electronic Engineering, Hezhou University, Hezhou Guangxi 542899, \\ China; \\ ${ }^{2}$ Guangxi Chung Chung energy saving Polytron Technologies Inc, Liuzhou Guangxi 545000, China; \\ ${ }^{3}$ College of Computer Science and Information Engineering, Hezhou University, Hezhou Guangxi \\ 542899, China. \\ ajanliful@163.com, ${ }^{b} 229292710 @ q q . c o m$
}

Keywords: electronic code lock; 1602 LCD; single-chip microcomputer.

\begin{abstract}
Starting from the point of view of simple and practical, using STC89C52 and low power CMOS type E2 PROM AT24C02 as main control chip and the data memory unit, combined with external matrix keyboard input,1602 LCD, alarm, unlock and other circuit modules to make electronic code lock is introduced in this paper. It can achieve the following functions: unlock when enter the correct password; alarm when enter the wrong password; code can be changed according to users' needs. The design method of code lock is reasonable, simple, safe and practical, with low cost, high flexibility, confidentiality and other advantages, which has a very good promotional value.
\end{abstract}

\section{Introduction}

In today's society, anti-theft security has become a social issue. Since ancient times, lock has been an important theft-proof tool. However, most people in China are still using traditional mechanical lock now, although the probability of unlocking a counterfeit mechanical lock with foreign keys is extremely high at present. This paper starts from economical and practical angle, by adopting SCM as the main control chip, combined with peripheral circuit to compose electronic code control system. The password of combination lock has 6 digits, each with the value range of 1 to 6 , set and changed by users themselves. And each password button is set with warning alarm and light. To open the lock, correct password should be input in the keyboard offered, during which prompt will occur when there is an input error. In order to improve safety, after the password is entered incorrectly for three times, it will give an alarm for ten minutes, during which period the entry of password is invalid, to prevent from malicious trial and error. Only when the six digs are input correctly, can the lock be opened (Zheng 2015). There is standby battery in the lock, only when the interior is power-on reset, can the password be set or changed. It is not allowable to modify or set the password with keys outside the door to ensure great security and elasticity.

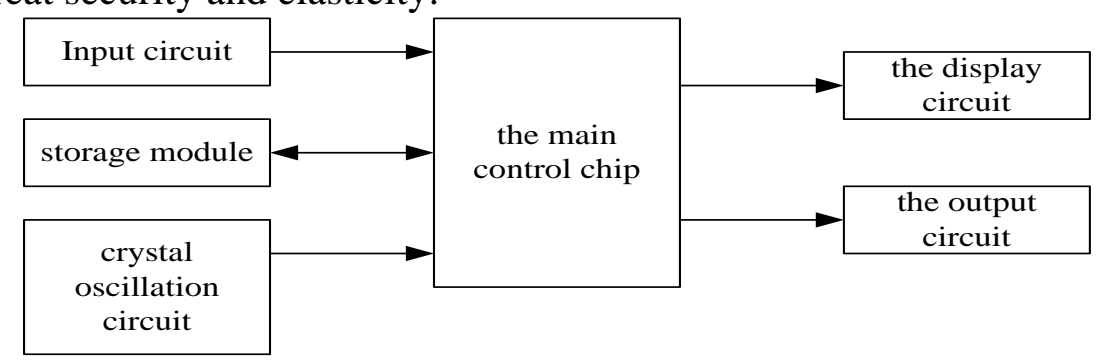

Fig. 1 block diagram of the entire design of the system

\section{Circuit Design}

This design uses single chip STC89C52 as the main control chip, combined with peripheral circuit matrix keyboard, LCD LCD1602 and password store AT24C02 and other parts. (ZHENG Shi-yong 2015). Wherein the matrix keyboard is used for entering numerical passwords and realize various 
functions (Zheng 2015). Enter the password with matrix keyboard connected to SCM, and then compare the input password and saved password to determine whether the password is correct, and then control the high and low level of pin to transit it to the unlocking circuit or alarm circuit for unlocking or giving an alarm. The overall system design block diagram is shown in Figure 1:

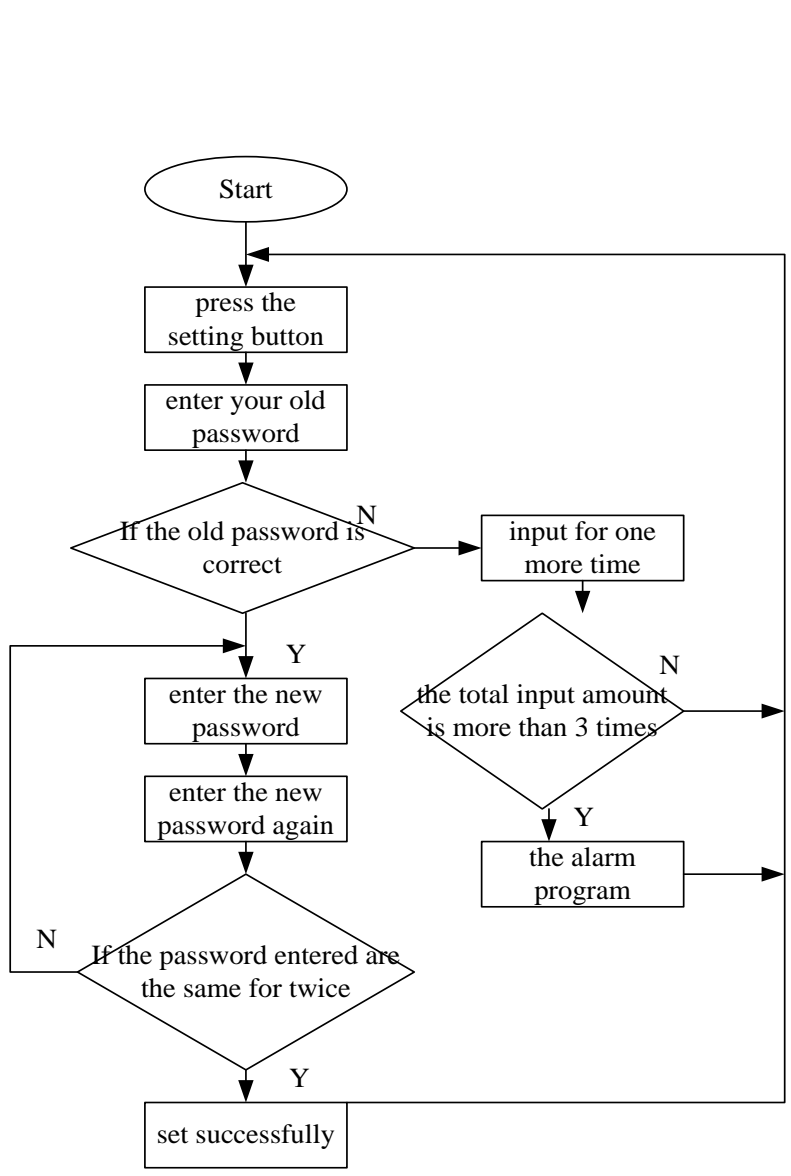

Fig. 2 the flow chart of password setting

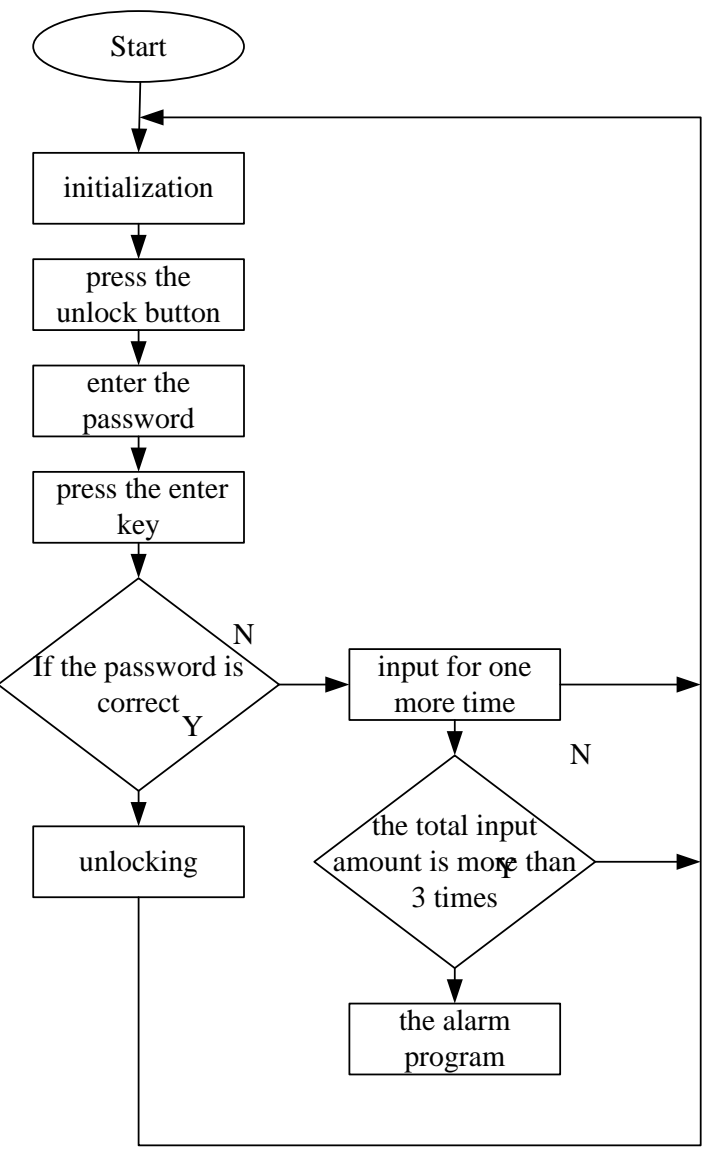

Fig. 3 unlocking flow chart

In system operation, initialize the program settings, and then enter the password on the keyboard, and then the system scans the keyboard. If the password is correct, it will be unlocked successfully, if it is input wrong for three times, there will be an alarm. (Zheng 2016).

Figure 2 is a flow chart of password settings. Press the set key, enter the old password. If it is entered wrong for totally three times, it enters into the alarm program (Zheng 2015). Figure 3 is a flow chart of unlocking. Press the unlock button, enter the password, if it is entered correctly, it will be unlocked successfully. If it is entered wrong for totally three times, it will perform the alarm program.

\section{Conclusion}

The electronic combination lock is designed to be input password on the keyboard manually. With an increasingly better high-tech today, the remote control becomes increasingly more important. In the future, the electronic combination lock will possess password key input remote interaction technology assisted by infrared technology or radio technology, which is able to realize password input by long-distance control. The traditional mode of entering password with keys may be abandoned, while voice control with the use of sensor technology, or face recognition technology, or fingerprint input method will be used, to make it more convenient to unlock the door. 


\section{Acknowledgments}

This work is supported the following fund:

2016 The project of improving the basic ability of young teachers in Colleges and universities in Guangxi: "Design and development of electronic commerce platform of agricultural products based on Semantic Technology” (No, KY2016YB455).

2016 Guangxi higher education teaching reform project: "Exploration on the cultivation mechanism of the teaching characteristics of Communication Engineering Specialty Based on ZTE ICT education platform"

2015 college students' innovative training program: "Research on the application of value added travel experience in the mobile terminal of the 'ethnic custom travel' in Guangxi" (No 201511838070); \&\& “The design and development HeYuanTong Campus Mobile Phone APP based on Android” (No 201511838034).

2015 Teaching case project construction project of hezhou university: “Tourist positioning and guiding system project of Huangyao scenic"; \&\& "Development and application of the information management system of 'Huang Yao Tong'”.

Project of scientific research and technology development project of Hezhou: "Design and implementation of agricultural products e-commerce platform based on Semantic Technology" (No, Hekeneng 1506006)

Scientific research project of hezhou university: "Research and development of E-government platform based on mobile terminal” (No 2015ZZZK03);

Reform in Education project of hezhou university: "Internet of things” (No hzxytszy201501); "Research on application personnel training model of Communications for SMEs" (No hzxyjg201525);

Master degree discipline construction scientific research and Cultivation Project: "Research on the social work service of the teenagers' Network Addiction” (No 2015SHGZ005) \&\&"Research on the intelligent development of rural tourism in Guangxi based on the Internet of things" (No 2015MTA16);

\section{References}

[1] Zheng SQ, DZ; Qiang, Z; Li, BQ. Design and Implementation of Supermarket Personnel Management System Based On Java. In: Chen PZ, S, editor. 2nd International Conference on Education, Management and Computing Technology (ICEMCT); Tianjin, PEOPLES R CHINA: ATLANTIS PRESS; 2015. p. 1724-7.

[2] Li BG, WL; Zheng, SY; Yue, XG. OPTIMISATION DESIGN OF CORN PRECISION SEEDER BASED ON MULTI-ROUTE AND MULTI-CHANNEL CONTROL [J]. JOURNAL OF THE BALKAN TRIBOLOGICAL ASSOCIATION. 2015, 21(4A): 1215-23.

[3] Zheng SG, Weili; Li, Biqing; Social Work in Teen Addiction Correction Services Research under the New Situation. In: Wang JX, P, editor. 4th National Conference on Electrical, Electronics and Computer Engineering (NCEECE); Xian, PEOPLES R CHINA: ATLANTIS PRESS; 2016. p. 252-5.

[4] Zheng SG, WL; Li, BQ. Digital Display Design of Ethnic Clothing of Nanling. In: Liang ZL, X, editor. 4th International Conference on Mechatronics, Materials, Chemistry and Computer Engineering (ICMMCCE); Xian, PEOPLES R CHINA: ATLANTIS PRESS; 2015. p. 2805-8.

[5] Shiyong Zheng WG, Jing Wang, Biqing Li, Deze QIN. Analysis of Internet of Things Talent Training and Curriculum System Innovation. 3th International Conference on Education, Management and Computiong Technology; Hangzhou, China: ATLANTIS PRESS; 2016. p. 957-60. 